\title{
Development of Indicators for Measuring Organisational Capacity for Climate Change Adaptation
}

\author{
Kriengsak Panuwatwanich ${ }^{1}, \mathrm{Oz}$ Sahin $^{2}$ and Vaughan Copping ${ }^{3}$
}

\begin{abstract}
The primary aim of this research was to develop a set of indicators that can be used to evaluate the adaptive capacity of construction organisations for climate change adaptation. Drawing upon past research findings, four critical factors indicating organisational adaptive capacity were identified: Technology, Business Strategy, Political/Legal and Operational. Once the critical factors had been established, an Analytic Hierarchical Process (AHP) was performed, using an input from eight industry experts from major construction organisations around Australia, to rank the importance of the identified factors and their associated indicators. These industry experts were asked to provide judgment based on a series of pairwise comparison through a questionnaire survey. The most significant aspect of this analysis was to develop the weighted importance index of each critical factor and indicator. The importance indices can be further applied to developing an assessment framework based on a scoring system, which can be used to measure the adaptive capacity of a construction organisation.
\end{abstract}

Keywords: Adaptation, Australia, capacity, climate change, construction

\section{Introduction}

The existing responses to climate change challenge generally take the forms of: 1) Mitigating (mainly by reducing greenhouse gasses); and 2) Adapting to the impact of climate change (Berkhout et al., 2006). Since the publication of the IPCC Fourth Assessment Report in 2007, a large assortment of adaptive actions has taken place in response to observed climate impacts. Adaptation plans are being developed and documented at the national, subnational, and community levels and by the private sector; however, there is still limited evidence of adaptation implementation. Implementation remains challenging because in the transition from planning to implementation the many interested parties must overcome resource, institutional, and capacity barriers (Mimura et al., 2014). Being the predominant focus of current climate change research, the adaptation approach acknowledges the fact that climate change, to some extent, is inevitable and is already occurring; it therefore focuses on adjustment to the climate change impacts (Adger et al., 2005). The Intergovernmental Panel on Climate Change (IPCC) defines adaptation as: The process of adjustment to actual or expected climate and its effects. In human systems, adaptation seeks to moderate or avoid harm or exploit beneficial opportunities. In some natural systems, human intervention may facilitate adjustment to expected climate and its effects (IPCC, 2014b). Adaptation however

\footnotetext{
1 Senior Lecturer, Griffith School of Engineering, Griffith University, Queensland, Australia, Tel: +617 5552 7357, E-mail: k.panuwatwanich@griffithuni.edu.au

2 Research Fellow, Griffith School of Engineering, Griffith University, Queensland, Australia, Tel: +617 5552 7378, E-mail: o.sahin@griffith.edu.au

3 Mechanical Engineer, Rio Tinto, Australia, Tel: +618 9327 2000, E-mail: vaughan.copping@riotinto.com
} 
is seen as being relatively complex and research into this approach is still in an early stage; this is particularly true among many economic sectors where adaptation involve interplay of economic variables and climate change impacts (Hertin et al., 2003). From business perspective, climate change impacts pose potential risks and opportunities, and being able to adapt to climate change is becoming an important part of an organisation's strategy (Sussman et al., 2008).

The Construction Industry is one of the primary economic sectors affected by the impacts of climate change (Sussman et al., 2008). The construction community has for some time been aware of the risks and opportunities associated with greenhouse gas mitigation as well as current and future climate change policies. Many construction organisations have taken steps to reduce greenhouse gas emissions voluntarily, including addressing the impacts of climate change (Adger et al., 2005). However, little is known regarding the existing measures, if any, taken by these organisations in adapting to climate change impacts. Adaptive capacity, as described by IPCC (2014a), is the ability of systems, institutions, humans, and other organisms to adjust to potential damage, to take advantage of opportunities, or to respond to consequences. An understanding of this process is important because it will allow analysts and decision makers to assess vulnerabilities and potential future damages; explore the more subtle indirect effects of climate change; and provide knowledge for better choices about how to achieve efficient, effective and equitable adaptation. It was thus the primary aim of this research to develop a set of indicators that can be used to evaluate the adaptive capacity of construction organisation in adapting to the climate change challenge. Additional outcomes will include a greater understanding of how construction organisations respond to these impacts and whether climate change adaptation procedures are in place among construction organisations.

\section{Theoretical Background}

\section{Climate change and business organisations}

It is widely acknowledged that climate change is reality and has already imposed new stresses on both natural and socio-economic systems. Reducing the risks from climate change requires both global actions to reduce the accumulation of greenhouse gases in the atmosphere to slow the rate of change (i.e. mitigation) as well as making adjustments in practices and policies that take a changing climate into account (i.e. adaptation). However, because most experts believe that even if mitigation measures were successful in substantially reducing the emission of these gases into the atmosphere, some extent of climate change is inevitable (Hertin et al., 2003). As a result, climate change adaptation is considered to have high priority and requires urgent attention and action across all levels of societies, organisations and individuals.

From a business perspective, climate change impacts pose potential risks and opportunities, and therefore being able to adapt to climate change is becoming an important part of an organisation's strategy. In many cases, while companies are well used to managing business risk, they have yet to integrate the long-term risks of climate change into these systems; nor are they preparing to grasp the competitive advantages that will accrue to those taking early action (Noble et al., 2014). A survey by West and Brereton (2013) of Australian businesses concluded that most were only vaguely aware of the breadth of adaptation actions that may be required and concerned about information sharing and disclosure. Construction is one of the major economic sectors affected by the impacts of climate change. The construction community has for some time been aware of the risks and opportunities 
associated with greenhouse gas mitigation and current and future climate change policies (Berkhout et al., 2006). In terms of risks, a construction project may face disruptions to construction sites and the delivery of materials as a result of damaged transportation infrastructure caused by severe storms. Usually high temperatures may reduce the amount of time that workers can safely engage in some activities. Conversely, opportunities may exist in the reduction of work stoppages caused by frost, thereby extending the portion of the year during which construction is possible. As such, understanding climate change impacts is becoming important as it will allow organisations to assess vulnerabilities and potential future damages as well as explore the potential effects of climate change; this can enable the organisations to make informed decisions as to whether, and how, to adapt to climate change (Berkhout et al., 2006).

Past research has determined that climate change can have direct and indirect impacts on organisations, and organisations may have three possible adaptation options: 1) Commercial; 2) Financial; and 3) Technological adaptations (Benner et al., 2003). Another study by KPMG International in 2008, based on published reports and interviews to identify the sectors where businesses considered they face the greatest climate-related risk, identified core risks as: regulatory, physical, reputational, and litigation risks (as cited in Noble et al., 2014). It is essential to recognise the significance of this process as it provides analysts with a means of assessing potential future damages and vulnerabilities as well as the knowledge needed to make more educated choices regarding effective, equitable and efficient adaptation. The fiscal implications of adaptation practices would be a primary factor in an organisation's desire to change. Government incentives have been used to encourage change; however construction organisations are still reluctant as the effort needed to adjust is believed to be far beyond the cause.

\section{Critical Factors and Indicators for Measuring Adaptive Capacity}

In order to build future adaptive capacity it is important to reduce the current adaptation deficit along with designing effective risk management and climate change adaptation measures (Noble et al., 2014). Through the ongoing research into climate change impacts and adaptation among Australian construction organisations, it has been determined that adaptive behaviour is patterned by specific internal resources and external conditions, and is therefore difficult to predict and subject to various limitations (Berkhout et al., 2006). To understand the adaptation process among organisations, a number of research studies have been conducted to identify the factors and indicators that reflect the underlying capabilities of organisations in adapting to climate change. Many of these findings are also relevant and applicable to the context of construction organisations. Broadly, the indicators of climate change adaptive capacities identified from these studies can be grouped into four factors: Technology, Business Strategy, Legal and Operational. These factors, along with their associated indicators and descriptions, are also summarised in Table 2.

\section{Technological factor}

Companies tend to respond to the impacts of climate change on a technical level if climate change is seen to have a significant physical impact on their core business (Berkhout, et al., 2006). According to Sanders and Phillipson (2003), climate change will have an impact on the existing building stock and require changes to current construction practices/technologies for new buildings. In this case, construction companies will be required to undergo a technological adaptation, based on Berkhout et al. (2006)'s adaptation space model. This means they will need to be aware and to understand the possible impacts 
caused by climate change as well as be able to adopt and apply new technologies/methods to make their products more resilient to the changing climate (Hertin et al., 2003). To achieve this, an investment in new technologies and to acquire know-how and necessary resources can be foreseen. Because climate change adaptation is a continuous process, companies will also require the procedures to train their employees to maintain their knowledge of available technologies and to stay up to date with changing technical environment (Adger et al, 2005).

\section{Strategic factor}

Sussman and Freed (2008) highlight the need for business organisations to develop strategies for managing risks associated with the physical effects of climate change in order to be able to react and adapt to it. In particular, they emphasise importance of the inclusion of risk management in a business planning and the use of risk sharing and transfer among project partners. In fact, risk management is already a core element of construction projects. Therefore, construction organisations should be able to incorporate climate change risks into their project planning and the formation of project partners/alliances. Hertin et al. (2003) similarly acknowledge business strategy as a primary factor in climate change adaption based on their research within the UK house building sector. The authors highlight the importance and effects of insurance policies and a contingency budget to accommodate the risks arising from the effects of climate change. Provisions for adequate insurance policies are also recommended to safeguard against negative climate change impacts (Sussman and Freed, 2008).

\section{Regulatory factor}

Not only can climate change have direct physical impacts on a company's products and/or services, it can also indirectly signal the need for adaptation to companies through changing regulatory frameworks by local or federal authorities that have actioned such change based on scientific evidence of climate change impacts. In fact, the range of adaptation options available to a company is profoundly influenced by the regulatory context within which a company operates (Berkhout et al., 2006). Given that compliance with local and federal regulations is one of the critical requirements for any construction projects to be undertaken, it is important for construction companies to be flexible and keep up to date with new/changing regulations being approved by the government in response to climate change impacts. Such flexibility is one key indicator of the effectiveness of an adaptation action according to Adger et at. (2005). Furthermore, it is beneficial that members of the organisation establish good relationships with regulators who drive the adaptation process (Hertin et al., 2003). This can be done through, for example, partaking in policy negotiations and attending conferences/meetings associated with policy change.

\section{Operational factor}

Physical impacts of climate change can cause ripple effects along the construction value chain. For example, extreme weather events (extreme temperature, increased rainfall and wind, etc.) may disrupt transport for site deliveries as well as affect some construction processes and onsite workers, causing increased work stoppages and subsequent delays (Sussman and Freed, 2008). In this case, construction companies would need to adapt their procedures to reduce impacts on suppliers, fabrication, transportation etc., in order to offset and/or mitigate the effects of such extreme events on the project lifecycles and/or companies' operations. Furthermore, because building adaptive capacity involves raising the awareness of climate change impacts and the need to adapt, effective internal communication is needed 
in order to raise awareness of employees regarding the potential impacts of climate change on construction sites and operations (Adger et al., 2005; Hertin et al., 2003).

Table 1. Critical factors and indicators

\begin{tabular}{|c|c|c|}
\hline Critical Factors & Indicators & Description \\
\hline \multirow[t]{4}{*}{ Technological } & Investment in new technology & $\begin{array}{l}\text { Investment in the form of money and manpower in } \\
\text { order to withstand future extreme conditions. } \\
\text { New technologies include higher quality construction } \\
\text { materials, skilled labour required to use new } \\
\text { technology, improved design process (lower costs, } \\
\text { increased workability) etc. }\end{array}$ \\
\hline & $\begin{array}{l}\text { Implementation/Utilisation of } \\
\text { available technologies }\end{array}$ & $\begin{array}{l}\text { - Employing qualified skilled personal to be able to } \\
\text { implement and/or use current technology }\end{array}$ \\
\hline & $\begin{array}{l}\text { Procedures to keep up-to-date with } \\
\text { new technologies }\end{array}$ & $\begin{array}{l}\text { Ensuring organisational procedures are in place to train } \\
\text { and maintain employer knowledge of current } \\
\text { technologies utilised by the company as well as other } \\
\text { available technologies in the industry }\end{array}$ \\
\hline & $\begin{array}{l}\text { Awareness of the impact of climate } \\
\text { change on construction } \\
\text { technologies }\end{array}$ & $\begin{array}{l}\text { - } \quad \text { Research and development undertaken by the } \\
\text { organisation into climate change impacts on its works }\end{array}$ \\
\hline \multirow[t]{4}{*}{ Strategic } & $\begin{array}{l}\text { Risk sharing/transfer arrangement } \\
\text { with construction partners }\end{array}$ & $\begin{array}{l}\text { - The sharing/transferring of risk associated with climate } \\
\text { change due to the forming of project alliances or } \\
\text { construction contractors. }\end{array}$ \\
\hline & $\begin{array}{l}\text { Procedures to evaluate risks from } \\
\text { climate change impact on business }\end{array}$ & $\begin{array}{l}\text { Risk evaluation undertaken by the organisation from } \\
\text { past event data, current technology, risk assessment } \\
\text { matrices etc. }\end{array}$ \\
\hline & $\begin{array}{l}\text { Provisions for adequate insurance } \\
\text { policies }\end{array}$ & $\begin{array}{l}\text { - } \quad \text { Ensuring enough investment into insurance policies to } \\
\text { safeguard against negative climate change impacts. }\end{array}$ \\
\hline & $\begin{array}{l}\text { Provisions for contingency budget } \\
\text { during extreme event }\end{array}$ & 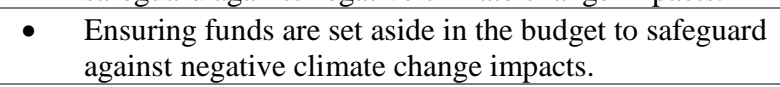 \\
\hline \multirow[t]{3}{*}{ Regulatory } & $\begin{array}{l}\text { Procedures to keep up-to-date with } \\
\text { changing regulation }\end{array}$ & $\begin{array}{l}\text { Ensuring an organisational unit is aware of current } \\
\text { regulations as well as new/changing regulation being } \\
\text { approved by the government. }\end{array}$ \\
\hline & $\begin{array}{l}\text { Participation in influencing climate } \\
\text { change policy }\end{array}$ & $\begin{array}{l}\text { Members of the organisation are being active with } \\
\text { policy negotiations including attendance at } \\
\text { conferences/meetings associated with policy change. }\end{array}$ \\
\hline & Flexibility to adopt new policies & $\begin{array}{l}\text { Organisations must remain flexible with current work } \\
\text { procedures to enable little or no disruption is } \\
\text { experienced as a result of new policies }\end{array}$ \\
\hline \multirow[t]{4}{*}{ Operational } & $\begin{array}{l}\text { Procedures to handle the disruption } \\
\text { of supply chain due to extreme } \\
\text { events }\end{array}$ & $\begin{array}{l}\text { - The procedures needed to reduce impacts on suppliers, } \\
\text { fabrication, transportation etc. }\end{array}$ \\
\hline & $\begin{array}{l}\text { Procedures to mitigate the impact of } \\
\text { extreme events on construction sites }\end{array}$ & $\begin{array}{l}\text { - The procedures implemented to decrease effects of } \\
\text { extreme events on the project lifecycle and/or company } \\
\text { operations. }\end{array}$ \\
\hline & $\begin{array}{l}\text { Human Resources training into the } \\
\text { awareness of risks and impacts due } \\
\text { to climate change }\end{array}$ & $\begin{array}{l}\text { Ensuring adequate training given to all organisational } \\
\text { personal aimed at increasing risk awareness associated } \\
\text { with climate change. }\end{array}$ \\
\hline & $\begin{array}{l}\text { Awareness of climate change } \\
\text { impact on construction operations }\end{array}$ & $\begin{array}{l}\text { Raising employer awareness of direct and in-direct } \\
\text { impacts that climate change imposes on construction } \\
\text { operations. }\end{array}$ \\
\hline
\end{tabular}

\section{Research Methodology}

\section{Stage One: Literature Review}

An extensive literature review was carried out to obtain a wider knowledge of the factors that influence the adaptive capacity of construction companies, in conjunction with climate 
change adaptation. Furthermore, the literature review provided a chance to acquire a greater understanding of the affects, consequences and possible solutions climate change poses on construction organisations globally. This lead to the development of the critical factors, and subsequent indicators, that affect the adaptive capacity among construction organisations, during climate change adaptation. Following this, the Analytic Hierarchy Process (AHP) was chosen to accurately quantify the importance of these factors based on the opinions of experienced industry professionals, as described in the sections below.

\section{Stage Two: Data Collection}

A pair-wise questionnaire was developed for the purpose of an Analytic Hierarchy Process (AHP) analysis. The AHP method depends on a model represented by four critical factors and 15 sub factors (indicators). These critical factors and indicators formed the foundation of the research questionnaire.

In this study, the questionnaire was carried out on small, medium and large scale construction companies in Australia. This allowed a more diverse framework to be developed. The questionnaire targeted industry professionals including general managers, projects managers, supervisors, senior project engineers and project engineers with ranging levels of experience and academic qualifications. Due to the limitations of project cost and scheduling the questionnaire was distributed through e-mail. The questionnaire provided an example on how to fill in the form to aid the participants in successful and accurate completion of the forms. Any misunderstandings were resolved through online communications with the relevant professionals.

\section{Stage Three: Data Analysis}

The Analytic Hierarchy Process (AHP) is a decision aiding method developed by Saaty (Saaty, 1980). It aims to prioritise a given set of factors or alternatives one ratio scale, based on the decision of the decision-maker, and stress the significance of natural judgments of a decision maker as well as the stability of the comparison of alternatives in the decision making process. Since a decision maker bases a judgment on knowledge and experiences and then makes decisions accordingly, the AHP technique agrees well with the behaviour of the decision maker. The power of this approach is that it systematises tangible and intangible factors in a systemic method, and supplies a simple solution to decision making problems (Skibniewski \& Chao, 1992). Furthermore, by breaking a problem down into a reasonable style from the large to smaller segments, one is able to connect the small issue to the objective through simple paired comparison judgments.

The SuperDecisions computer software program was used to perform the AHP analysis in this project. The SuperDecisions is a freely available decision making software based on the Analytic Hierarchy Process (AHP) and the Analytic Network Process (ANP) developed by Saaty (SuperDecisions, 2015). The program provided a powerful tool to handle all the complexities of mathematical equations of the prioritising process in the AHP hierarchical decision structure. Figure 1 illustrates the AHP model used in this research. 


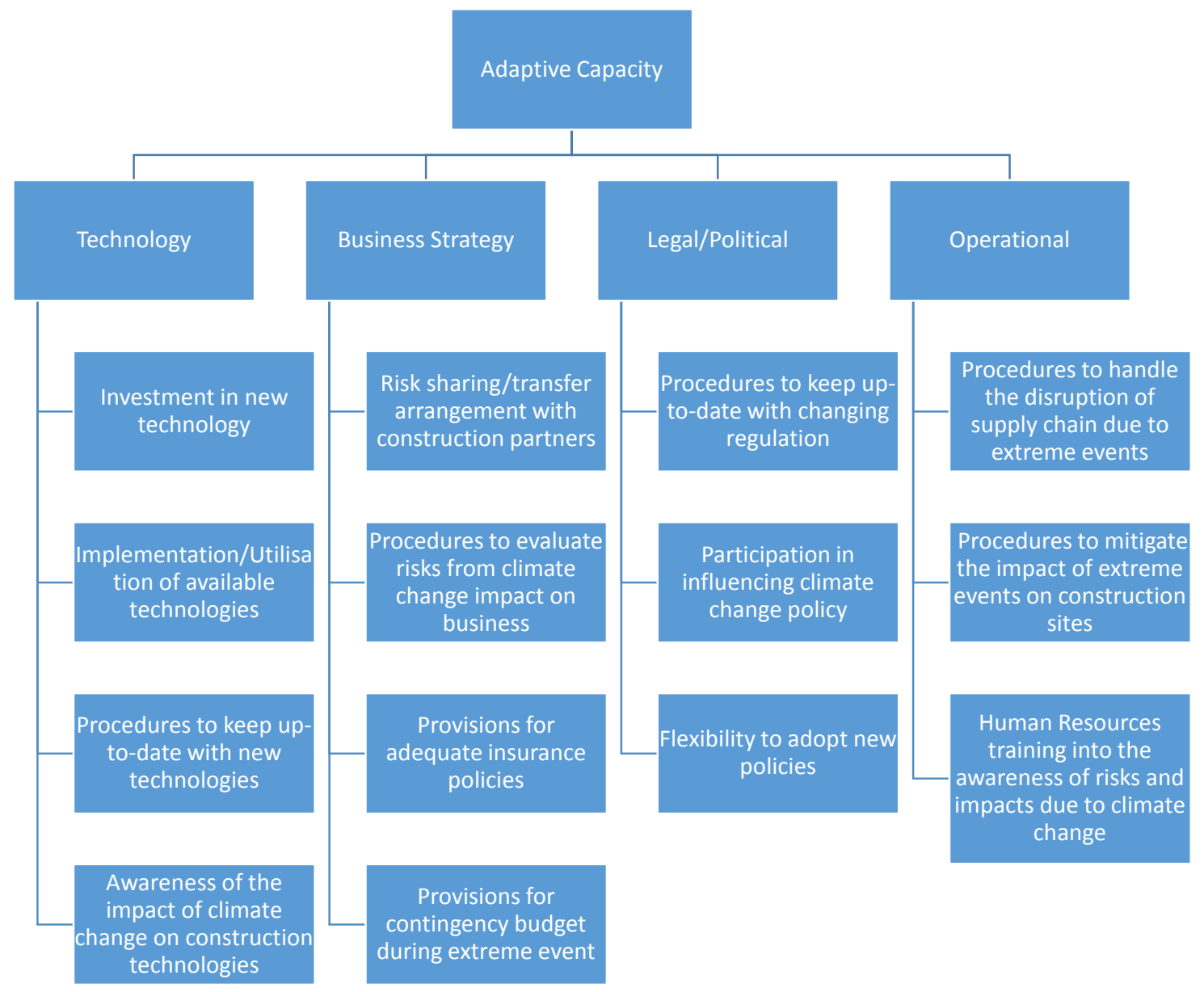

Figure 1. AHP model

\section{Results and Discussion}

\section{Sample Characteristics}

In total, 20 questionnaires were distributed to 20 different construction organisations with 12 responses were received in time to undergo analysis. The criteria for selecting targeted participants are: they must hold a senior level position in the company with at least 5 years of experience in the construction industry. Of the 12 responses however, only eight were suitable for analysis due to the inconsistency of four questionnaires. One of the strengths of the AHP would most certainly be the ability to carry out a check for the consistency of participants' pair wise judgements. In general life circumstances, the consistency of successive judgements has the potential to be quite low; a low consistency of judgements implies a high inconsistency. This is a natural occurrence in decision making, particularly when the criteria considered is diverse (Banai, 2006). AHP methodology allows the inconsistency of every participant's survey responses to be represented by the consistency ratio (CR). A high CR implies that judgements have a high level of inconsistency. In most cases, the CR should be $\leq 0.10$ to be acceptable, which implies that the judgements have $10 \%$ inconsistency and $90 \%$ consistency; in some cases, $\mathrm{CR} \leq 0.20$ could be tolerated (Saaty and Kearns, 1985). It should be noted that in AHP, there is no rule regarding minimum sample size requirement as the AHP is not a statistical technique. As clearly attested to in a study, AHP is a subjective method, and so it is not necessary to involve a large sample (Wong and 
$\mathrm{Li}, 2008$ ), and additionally, the survey process may be impractical with a large 'cold-called' sample, as the participants may have a tendency to provide arbitrary answers, resulting in a very high degree of inconsistency (Cheng and $\mathrm{Li}$, 2002). Thus, the emphasis is rather on the need for AHP participants to have expert knowledge in the subject matter relevant to the AHP exercise (Saaty and Vargas, 2012).

Half of the organisations involved in the study employed between 31 and 100 workers, with a quarter of the organisations employing between 101 and 200 workers. All of the participants involved held positions of responsibility in the company with the majority including Project Managers (37\%), followed by Senior Project Engineers (25\%). The majority of the participants (63\%) also have over ten years of experience.

\section{AHP Results}

Super Decisions program was employed to calculate the importance indices of each factor and indicator using the pair-wise comparison data obtained from the eight industry professionals. To aggregate the results from all the eight industry professionals, the importance indices for each factor and indicator were averaged. The average AHP weighting score was adopted for each critical factor and indicator due to the variety of AHP weighting opinions, amongst the industry professionals. This process allows the four critical factors and fifteen indicators to be ranked with respect to the level of importance, in each group. The rankings of each factor and indicator are presented in Tables 2 to 6 . It should be noted all consistency ratios are within the recommended values of 0.10 .

According to Table 2, it can be seen that with an average weighted score of just under 0.5 , the "Operational" factor is viewed as the most important relative to the others, whereas Technology is the least important. The reason behind the apparent importance of Operations could be due to its direct daily impact on the construction site in terms of safety and project progress. This is in contrast to a factor such as Technology, whereby it is seen as more of an investment for the future.

Table 2. Average importance index and ranking for all critical factors

\begin{tabular}{ccc}
\hline CRITICAL FACTORS & $\begin{array}{c}\text { AVERAGE } \\
(\mathbf{n = 8})\end{array}$ & RANK \\
\hline Technology & 0.062 & 4 \\
Business Strategy & 0.293 & 2 \\
Legal/Political & 0.148 & 3 \\
Operational & 0.497 & 1 \\
& $\Sigma 1.000$ & \\
\hline
\end{tabular}

Tables 3 to 6 present the weighted score comparisons of technology, business strategy, legal/political and operational indicators of organisational adaptive capacity, respectively. As for the "Technology" indicators, it can be seen that these organisations perceived the ability to implement and/or utilise available technologies as the most important indicator. When considering "Business Strategy", the provisions for contingency budget during extreme events was seen as the most important indicator, followed closely by provisions for adequate insurance policies. Flexibility to adopt new policies was emphasised strongly as the most important indicator in the legal/political category. Lastly, two indicators that were closely perceived as most important to reflect "Operational" adaptive capacity are "procedures to mitigate the impact of extreme events on construction sites" and "ensuring 
employer's awareness of construction safety due to extreme events”. It can be seen that all the indicators perceived as most important within each critical factor appear to focus on those activities that are directly relevant to, or have an immediate impact on, the companies' dayto-day business.

Table 3. Average importance index and ranking for "Technology” indicators

\begin{tabular}{lcc}
\hline \multicolumn{1}{c}{ TECHNOLOGY } & $\begin{array}{c}\text { AVERAGE } \\
(\mathbf{n = 8})\end{array}$ & RANK \\
\hline A.1 Investment in developing new climate change related & 0.086 & 4 \\
technology & 0.432 & 1 \\
A.2 Implementation/ Utilisation of available technologies & 0.199 & 3 \\
A.3 Procedures to keep up to date with new technologies & 0.283 & 2 \\
A.4 Awareness of climate change on construction technologies & $\sum 1.000$ & \\
\hline
\end{tabular}

Table 4. Average importance index and ranking for "Business Strategy” indicators

\begin{tabular}{lcc}
\hline \multicolumn{1}{c}{ BUSINESS STRATEGY } & $\begin{array}{c}\text { AVERAGE } \\
(\mathbf{n = 8})\end{array}$ & RANK \\
\hline B.1 Risk sharing arrangement with construction partners & 0.176 & 3 \\
B.2 Procedures to assess risks from climate change impact on & 0.107 & 4 \\
business & 0.343 & 2 \\
B.3 Provisions for adequate insurance policies & 0.374 & 1 \\
B.4 Provisions for contingency budget during extreme events & $\sum 1.000$ & \\
\hline
\end{tabular}

Table 5. Average importance index and ranking for "Legal/Political” indicators

\begin{tabular}{lcc}
\hline \multicolumn{1}{c}{ LEGAL/ POLITICAL } & $\begin{array}{c}\text { AVERAGE } \\
(\mathbf{n = 8 )}\end{array}$ & RANK \\
\hline C.1 Procedures to keep up to date with changing regulations & 0.310 & 2 \\
C.2 Participation in influencing climate change policy & 0.154 & 3 \\
C.3 Flexibility to adopt new policies & 0.536 & 1 \\
& $\sum 1.000$ & \\
\hline
\end{tabular}

Table 6. Average importance index and ranking for “Operational” indicators

\begin{tabular}{lcc}
\hline \multicolumn{1}{c}{ OPERATIONAL } & $\begin{array}{c}\text { AVERAGE } \\
\text { (n=8) }\end{array}$ & RANK \\
\hline $\begin{array}{l}\text { D.1 Handling the disruption of supply chain and operations due to } \\
\text { extreme events }\end{array}$ & 0.154 & 3 \\
$\begin{array}{l}\text { D.2 Procedures to mitigate the impact of extreme events on } \\
\text { construction sites }\end{array}$ & 0.369 & 1 \\
$\begin{array}{l}\text { D.3 Human Resources training into the awareness of risks due to } \\
\text { climate change }\end{array}$ & 0.142 & 4 \\
$\begin{array}{l}\text { D.4 Ensuring employer's awareness of construction safety due to } \\
\text { extreme events }\end{array}$ & 0.335 & 2 \\
\hline
\end{tabular}




\section{Discussion and Conclusion}

The findings indicate that the experts participated in the study collectively viewed the operational factor (out of the four factors) as the most critical aspect of the adaptive capacity of their organisations in responding to climate change challenge. This implies that priority in terms of resources expended in enhancing adaptive capacities of the organisations should be on activities directly relevant to construction operations. More specifically, as suggested by the two operational indicators with highest weighting, these activities should be relevant to those procedures that can be implemented to mitigate the impact of extreme events on construction sites and ensuring employer's awareness of construction safety due to extreme events. In addition, the fact that most significant indicators within each factors are directly relevant to, or have an immediate impact on, the companies' day-to-day activities suggest that there is still much to be done in promoting long term capacity building initiatives focusing on technology investment, human resource development and business innovations.

Apart from providing a better understanding on how companies place an important on the critical factors and indicators that reflect the capacity to adapt to climate change challenge, the above findings could be further used in developing an assessment tool to measure the adaptive capacity of a construction company. To achieve this, a scoring technique can be used whereby a company is evaluated (e.g. using a scale of 5) on how well the company performs against each indicator within each factor. For each indicator, the evaluation score can then be weighted using relevant weightings as presented in Tables 3 to 6. The weighted scores from each indicator can then be summed to represent a weighted score for each factor. Using the similar process, the weighted factor scores are then multiplied with their respective weighting (Table 2) and summed to provide a total weighted score that represents a quantitative level of the company's adaptive capacity. This can serve as a potential future work that should be considered to further the findings from this study.

\section{References}

Adger, W. N., Arnell, N. W. and Tompkins, E. L., 2005. Successful adaptation to climate change across scales, Global Environmental Change, 15(2), 7-86.

Banai, R., 2006. Public Transportation Decision-Making: A Case Analysis of the Memphis Light Rail Corridor and Route Selection with Analytic Hierarchy Process. Journal of Public Transportation, 9(2), 1-24.

Benner, M. J. and Tushman, M. L., 2003. Exploitation, exploration, and process management: the productivity dilemma revisited, Academy of Management Review, 28(2), 238-256.

Berkhout, F., Hertin, J. and Gann, D. M., 2006. Learning to adapt: organisational adaptation to climate change impacts. Climatic Change, 78(1), 135-156.

Cheng, E. W. L. and Li, H., 2002. Construction partnering process and associated critical success factors: Quantitative investigation. Journal of Management in Engineering, 18(4), 194-202.

Hertin, J., Berkhout, F., Gann, D. and Barlow, J., 2003. Climate change and the UK house building sector: perceptions, impacts and adaptive capacity, Building Research and Information, 31(3), 278-290.

IPCC 2014a. Annex II: Glossary. In Climate Change 2014: Impacts, Adaptation, and Vulnerability. Part B: Regional Aspects. Contribution of Working Group II to the Fifth Assessment Report of the Intergovernmental Panel on Climate Change. Cambridge, United Kingdom and New York, NY, USA: Cambridge University Press. 
IPCC 2014b. Summary for Policymakers. In Climate Change 2014: Impacts, Adaptation, and Vulnerability. Part A: Global and Sectoral Aspects. Contribution of Working Group II to the Fifth Assessment Report of the Intergovernmental Panel on Climate Change. Cambridge, United Kingdom, and New York, NY, USA: Cambridge University Press.

Mimura, N., Pulwarty, R. S., Duc, D. M., Elshinnawy, I., Redsteer, M. H., Huang, H. Q., Nkem, J. N. and Rodriguez, R. A. S., 2014. Adaptation planning and implementation. In: Climate Change 2014: Impacts, Adaptation, and Vulnerability. Part A: Global and Sectoral Aspects. Contribution of Working Group II to the Fifth Assessment Report of the Intergovernmental Panel of Climate Change. Cambridge, United Kingdom and New York, NY, USA: Cambridge University Press.

Saaty, T.L., 1980. The Analytic Hierarchy Process, McGraw-Hill, Inc.

Saaty, T. L. and Vargas, L. G., 2012. Models, Methods, Concepts \& Applications of the Analytic Hierarchy Process. Springer Science \& Business Media.

Skibniewski, M., and Chao, L., 1992. Evaluation of advanced construction technology with AHP method, Journal of Construction Engineering and Management, 118(3), 577593.

Sussman, F. G. and Freed, J.R., 2008. Adapting to Climate Change: A Business Approach. PEW Center on Global Climate Change. 